\title{
ATRIBUTOS QUÍMICOS DE UM CAMBISSOLO E CRESCIMENTO DE MUDAS DE EUCALIPTO APÓS ADIÇÃO DE LODO DE CURTUME CONTENDO CROMO $^{1}$
}

\begin{abstract}
Ernani Lopes Possato², Walcylene Lacerda Matos Pereira Scaramuzza ${ }^{3}$, Oscarllina Lúcia dos Santos Weber $^{4}$, Rejane Nascentes ${ }^{5}$, André Luiz Bressiani ${ }^{6}$ e Natalino Calegario ${ }^{7}$

RESUMO - O processo de curtimento do couro gera resíduos com potencial de uso como corretivo e fertilizante, no entanto alguns de seus constituintes são tóxicos quando presentes em elevado teor no solo, o que limita sua utilização nos sistemas de produção. O objetivo deste trabalho foi avaliar as alterações nos atributos químicos de um Cambissolo Húmico e o crescimento e teor de Cr em clones de Eucalyptus urophylla após a adição de doses de lodo de curtume (LCT). O experimento foi realizado em casa de vegetação, no período de março a julho de 2009. Os tratamentos consistiram da adição de doses de lodo de curtume $(0 ; 1,5 ; 3,0 ; 4,5$; e 6,0 $\mathrm{g} \mathrm{dm}^{-3}$ ) ao solo, que recebeu, de forma complementar, calcário e adubação NPK em dose única. $\mathrm{O}$ pH, a condutividade elétrica, a relação de adsorção de sódio e a porcentagem de sódio trocável, relacionadas com a salinidade do solo, aumentaram com o incremento das doses do lodo de curtume, porém os valores observados ficaram abaixo dos níveis salinos. O teor de Cr solúvel no solo, extraído pela água, decresceu linearmente com o aumento das doses de LCT, correlacionando-se negativamente com o pH do solo. O aumento da dose do LCT proporcionou incremento na altura dos clones de Eucalyptus urophylla em até 11,5\% em relação à testemunha. A produção de massa das raízes secas decresceu, em média, 28,3\%, em relação à testemunha, com a maior dose (6 $\left.\mathrm{g} \mathrm{dm}^{-3}\right)$. As plantas de eucalipto, em todos os tratamentos, continham o Cr somente no sistema radicular, e, quanto maior a dose de LCT, maior o teor desse metal nas raízes.
\end{abstract}

Palavras-chave: Resíduo industrial; RAS; PST.

\section{CHEMICAL ATTRIBUTES OF A CAMBISOL AND GROWTH OF EUCALYPTUS SEEDLING AFTER THE ADDITION OF TANNERY SLUDGE CONTAINING CHROMIUM}

\begin{abstract}
The leather tanning process produces residues potentially useful as lime and fertilizer, however, some of its components are toxic to soil when in high concentration, which limits its use in production systems. The aim of this study was to evaluate the changes in the chemical properties of a Humic Cambisol and the growth and content of Chromium in Eucalyptus urophylla clones after the addition of tannery sludge (TS) doses. The experiment was conducted inside a greenhouse from March to July, in the year of 2009. The treatments consisted in the addition of tannery sludge doses $\left(0,1.5,3.0,4.5\right.$ and $\left.6.0 \mathrm{~g} \mathrm{dm}^{-3}\right)$ to the soil and also, as a complement, lime and NPK fertilization in a single dose. The $\mathrm{pH}$, electrical conductivity, sodium adsorption ratio and exchangeable sodium percentage, which are aspects related to soil salinity, increased when higher doses of tannery sludge were used. However, the values found were below the salinity levels. The soluble Cr
\end{abstract}

\footnotetext{
${ }^{1}$ Recebido em 21.07.2010 aceito para publicação em 02.07.2014.

${ }^{2}$ Programa de Pós-Graduação em Ciências Florestais e Ambientais, Universidade Federal de Mato Grosso, Brasil. E-mail: <epossato@yahoo.com.br>.

${ }^{3}$ Departamento de Solos e Engenharia Rural, Faculdade de Agronomia e Medicina Veterinária, Universidade Federal de Mato Grosso, Brasil. E-mail: <wlmperei@yahoo.com.br>.

${ }^{4}$ Departamento de Solos e Engenharia Rural, Faculdade de Agronomia e Medicina Veterinária, Universidade Federal de Mato Grosso, Brasil. E-mail: <oscsanwb@cpd.ufmt.br>.

${ }^{5}$ Departamento de Engenharia Civil, Universidade Federal de Viçosa, Campus Rio Paranaíba, Brasil. E-mail:<rejane.nascentes@ufv.br> .

${ }^{6}$ Banco da Amazônia S.A, Brasil. E-mail: <andrebressiani@hotmail.com>.

${ }^{7}$ Departamento de Ciências Florestais, Universidade Federal de Lavras. E-mail: <calegari@dcf.ufla.br>.
} 
content in the soil, which was extracted by water, linearly decreased when higher doses of TS were used and it was negatively correlated to soil $\mathrm{pH}$. Increasing doses of TS provided an increment in Eucalyptus urophylla clones height by $11.5 \%$ when compared to the control. The dry mass production of the roots decreased, on average, $28.3 \%$ when compared to the control, with the highest dose (6 $\left.\mathrm{g} \mathrm{dm}^{-3}\right)$. The Eucalyptus plants, in all treatments, had Chromium only in the roots system, and the highest the TS dose, the highest the levels of this metal in the roots.

Keywords: Industrial waste; SAR; ESP.

\section{INTRODUÇÃO}

A aplicação de resíduos industriais e urbanos em solos, para fins de fertilização, já ocorre em alguns setores produtivos, a exemplo da indústria de celulose, que utiliza parte dos resíduos gerados no processo de polpação, como fonte de cálcio e outros nutrientes em plantios florestais (BELLOTE et al., 1998), que abastecem de matéria-prima a própria indústria. Esse procedimento é estratégico para as empresas, de forma que possibilita a redução dos custos de implantação e manutenção de aterros industriais, utilizados para destinação desses resíduos, reduzindo também a quantidade de insumos necessários à produção vegetal.

A indústria curtumeira é geradora de resíduos sólidos (lodo de curtume) constituídos por matéria orgânica de origem animal e de sais inorgânicos com potencial fertilizante e de condicionante de acidez do solo, sendo seu uso investigado tanto em culturas agrícolas quanto florestais. No entanto, a presença de sódio (Na) e do metal cromo (Cr) nos resíduos dessa indústria é o principal limitante de sua utilização em sistemas de produção (AQUINO NETO; CAMARGO, 2000). O Na, devido à sua interação com os coloides, pode acarretar na dispersão das partículas do solo e, consequentemente, em sua movimentação no perfil, reduzindo a condutividade hidráulica (IRVINE; REID, 2001). Além disso, o teor elevado de outros sais no lodo, quando dissolvidos na solução do solo, pode elevar a pressão osmótica do meio, dificultando a absorção de água e nutrientes pela planta (RAIJ, 1991).

A presença do Cr aumenta a necessidade de controle no uso desse resíduo no solo, uma vez que o Cr é potencialmente nocivo aos seres vivos em razão, principalmente, do elevado poder oxidante da forma catiônica hexavalente $\left(\mathrm{Cr}^{+6}\right)$, que, juntamente com a forma trivalente $\left(\mathrm{Cr}^{+3}\right)$, compõe os estados de oxidação predominante do metal no solo (BARTLETT, 1991). Além do estado de oxidação, fatores como o teor de argila, de óxidos e hidróxidos, de matéria orgânica, o $\mathrm{pH}$, o potencial redox e o teor do próprio metal influenciam sua dinâmica de adsorção/dessorção e precipitação/dissolução no solo (ALLEONI et al., 2005), podendo ser, em qualquer dos seus estados de oxidação, absorvido e ocorrer em teor elevado nos tecidos da planta (GUPTA; SINHA, 2007).

A utilização do lodo de curtume na produção agrícola e, ou, florestal ainda requer investigação das consequências no solo, água e planta decorrentes do seu uso. Assim, o objetivo deste estudo foi avaliar os atributos químicos do solo, as características de crescimento e o teor de Cr em clones de Eucalyptus urophylla após a adição de doses de lodo de curtume.

\section{MATERIAL E MÉTODOS}

O experimento foi realizado em casa de vegetação da Faculdade de Agronomia e Medicina Veterinária (FAMEV) da Universidade Federal de Mato Grosso (UFMT), em Cuiabá, MT, entre os meses de março e julho de 2009. A média da temperatura e da umidade relativa do ar registrada na casa de vegetação durante o período experimental foi, respectivamente, igual a $30,8^{\circ} \mathrm{C}$ e $58,1 \%$.

O solo utilizado foi um Cambissolo húmico, sob Cerrado, coletado na camada superficial $(0-20 \mathrm{~cm})$ de textura muito argilosa (317 $\mathrm{g} \mathrm{kg}^{-1}$ de areia, $616 \mathrm{~g} \mathrm{~kg}^{-1}$ de argila e $67 \mathrm{~g} \mathrm{~kg}^{-1}$ de silte) (EMBRAPA, 1997). O solo foi seco ao ar e peneirado com malha de $5 \mathrm{~mm}$ e caracterizado segundo Embrapa (1997) (Tabela 1).

O lodo de curtume foi proveniente do tratamento primário das águas residuais do curtimento ao cromo (LCT) da indústria de curtume Durli Ltda., localizada no Distrito Industrial de Cuiabá, MT. O LCT foi seco ao ar, destorroado e peneirado em malha de $5 \mathrm{~mm}$, sendo caracterizado quimicamente de acordo com a metodologia descrita por Tedesco et al. (1995) (Tabela 1).

Em sacolas de plástico de $5 \mathrm{dm}^{3}$ de capacidade contendo $4 \mathrm{~kg}$ de solo, foram adicionadas doses de lodo de curtume, de forma a obter os seguintes 
Tabela 1 - Características químicas do Cambissolo Húmico e do lodo de curtume. Table 1 - Chemical characteristics of Humic Cambisol and tannery sludge.

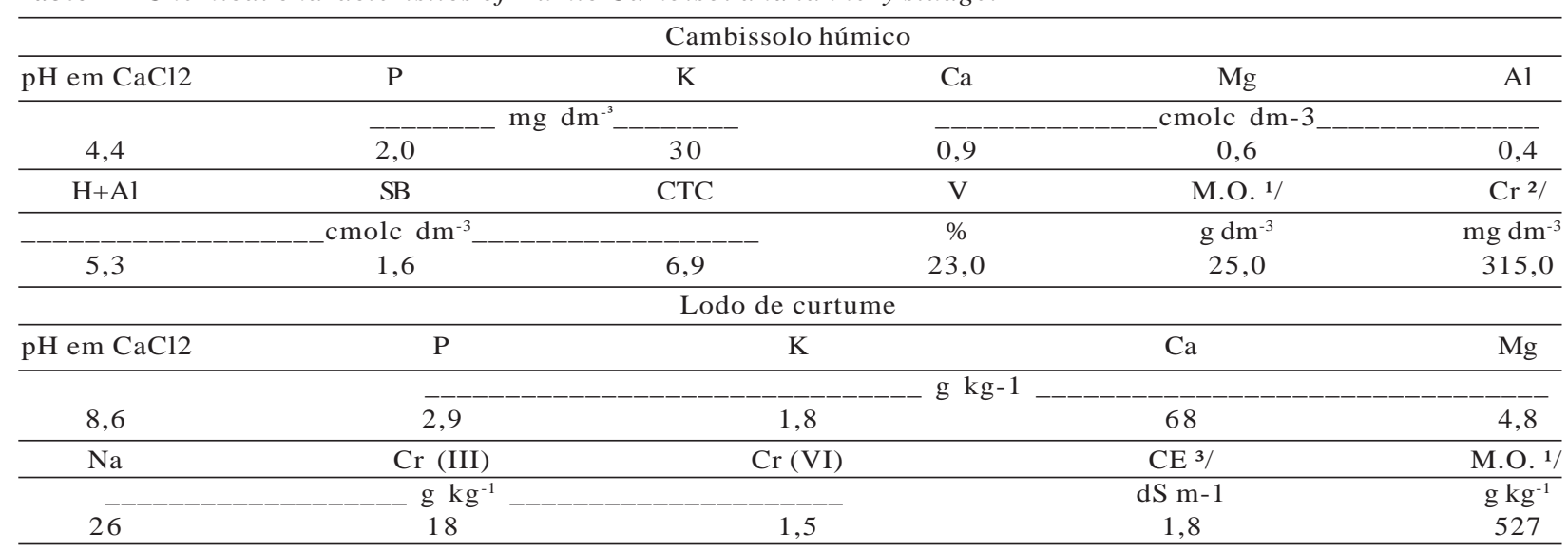

${ }^{1 /}$ Matéria orgânica; ${ }^{2 /}$ Cromo total no solo (TEDESCO et al., 1995); e ${ }^{3 / C o n d u t i v i d a d e ~ e l e ́ t r i c a . ~}$

1/ Organic matter; 2/ Total chromium in soil; 3/ Electrical conductivity.

tratamentos: solo (testemunha); solo $+1,5 \mathrm{~g} \mathrm{dm}^{-3}$ de LCT (LCT 1,5); solo + 3,0 g dm ${ }^{-3}$ (LCT 3); solo + 4,5 $\mathrm{g} \mathrm{dm}^{-3}$ (LCT 4,5); e solo + 6,0 $\mathrm{g} \mathrm{dm}^{-3}$ (LCT 6) (as doses foram calculadas na base seca). Em todos os tratamentos, no momento da mistura do solo com o lodo de curtume, aplicou-se o equivalente a 1,8 $\mathrm{Mg} \mathrm{ha}^{-1}$ de calcário dolomítico (CaO: 30\%, MgO: 20\%, PN: 103\% e PRNT: 99\%). Essa dose foi calculada conforme Raij (1981), com base na saturação inicial do Cambissolo Húmico, sendo suficiente para elevar a saturação por bases a 50\%, conforme recomendado para a espécie (SILVA et al., 2007). A mistura de solo, lodo de curtume e calcário foi mantida úmida e em condição aeróbica, durante 30 dias, para iniciar a mineralização do lodo e a reação do calcário.

Todos os tratamentos receberam adubação NPK, dose única, cinco dias antes do transplantio. Os nutrientes foram aplicados em solução, em cada unidade experimental, nas seguintes quantidades: $100 \mathrm{mg} \mathrm{dm}^{-3}$ de $\mathrm{N} ; 237 \mathrm{mg} \mathrm{dm}^{-3}$ de P; e $40 \mathrm{mg} \mathrm{dm}^{-3}$ de $\mathrm{K}$, tendo como fonte a solução P.A. (puro para análise) de $\mathrm{NH}_{4} \mathrm{H}_{2} \mathrm{PO}_{4}, \mathrm{KH}_{2} \mathrm{PO}_{4}$ eNH $\mathrm{NO}_{3}$, na proporção 36,8:6,7:1 (peso:peso). A quantidade de $\mathrm{P}$ e $\mathrm{K}$ foi estabelecida de forma que esses nutrientes atingissem o nível médio estabelecido na tabela de interpretação de análise de solo, conforme Alvarez V. et al. (1999), e a quantidade de N seguiu a recomendação de Novais et al. (1991) para dosagem básica em experimentos em casa de vegetação.
Foram utilizadas mudas clonais de Eucalyptus urophylla com 45 dias de idade, ou seja, tempo transcorrido após o estaqueamento, e produzidas em tubetes contendo substrato comercial. Cada muda foi transplantada em uma sacola plástica de $5 \mathrm{dm}^{3}$ de capacidade, sendo retirado das raízes o substrato comercial por meio da lavagem com água deionizada. Durante o experimento, as mudas foram irrigadas diariamente até a umidade próxima a $80 \%$ da capacidade máxima de retenção de água no solo, obtida por meio de pesagem.

Transcorridos os 120 dias do transplantio, as plantas foram mensuradas em altura e diâmetro do coleto. Em seguida, separou-se a parte aérea (caule e folhas) das raízes, as quais foram lavadas com água deionizada e submetidas à secagem em estufa de circulação forçada de ar a $70{ }^{\circ} \mathrm{C}$ até atingirem peso constante, sendo, posteriormente, pesadas para a determinação da massa seca. O material seco foi moído e, em seguida, digerido conforme Silva (1999) e utilizado na determinação do teor de Cr em espectrofotômetro de absorção atômica.

Após o cultivo, amostras de solo foram retiradas de cada unidade experimental para determinação do pH do solo e dos teores de K, Ca, Mg e Na e da acidez potencial (H+Al) (EMBRAPA, 1997), que são necessários ao cálculo da relação de adsorção de sódio (RAS) e da porcentagem de sódio trocável (PST), conforme Freire e Freire (2007). A condutividade elétrica (CE) foi determinada conforme Camargo et al. (1986). 
Para determinação do cromo solúvel no solo, foi feita uma suspensão de solo em água deionizada na relação de 1:2 (sólido:líquido). As amostras foram agitadas por $16 \mathrm{~h}$ em agitador horizontal, a $100 \mathrm{rpm}$, e, em seguida, centrifugadas a $4.000 \mathrm{rpm}$ durante 10 min, a $11^{\circ} \mathrm{C}$. A suspensão obtida após a centrifugação foi filtrada em papel de filtragem rápida e recolhida em frasco plástico para posterior determinação do teor do Cr em espectrofotômetro de absorção atômica.

Os dados foram submetidos ao teste de normalidade ( $p>0,10)$ e à análise de variância; no caso de significância pelo teste $\mathrm{F}(\mathrm{p}<0,05)$, procedeu-se à análise de regressão com o uso do programa SISVAR 5.1 (FERREIRA, 2008). Testaram-se os modelos lineares de primeiro e segundo graus para cada variável. O modelo escolhido foi aquele com melhor distribuição dos resíduos, contendo parâmetros significativos $(\mathrm{p}<0,05)$ pelo teste $\mathrm{t}$, e aquele com maior coeficiente de determinação $\left(\mathrm{R}^{2}\right)$.
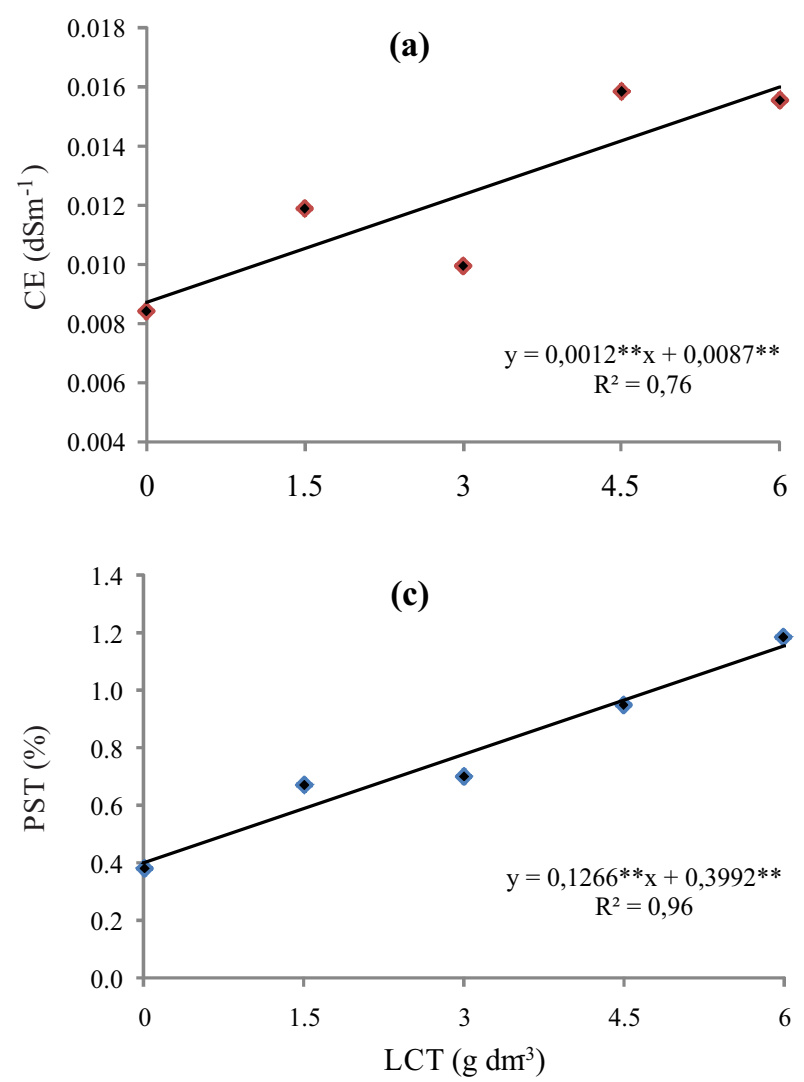

Foram determinados os coeficientes de correlação de Pearson correspondentes à associação linear entre as variáveis cromo solúvel no solo e pH do solo, utilizando-se o aplicativo computacional Minitab Release 14.13 (MINITAB, 2004).

\section{RESULTADOS}

Verificou-se que os valores de $\mathrm{pH}$, condutividade elétrica (CE), relação de adsorção de sódio (RAS) e porcentagem de sódio trocável (PST) aumentaram linearmente com as doses de LCT (Figura 1). Esses atributos são utilizados no diagnóstico da salinidade do solo, e o aumento em seus valores é esperado quando se adiciona o lodo de curtume, devido à sua composição rica em sais (AQUINONETO; CAMARGO, 2000; COSTA et al., 2001; KONRAD; CASTILHOS, 2002; TEIXEIRA et al., 2006).
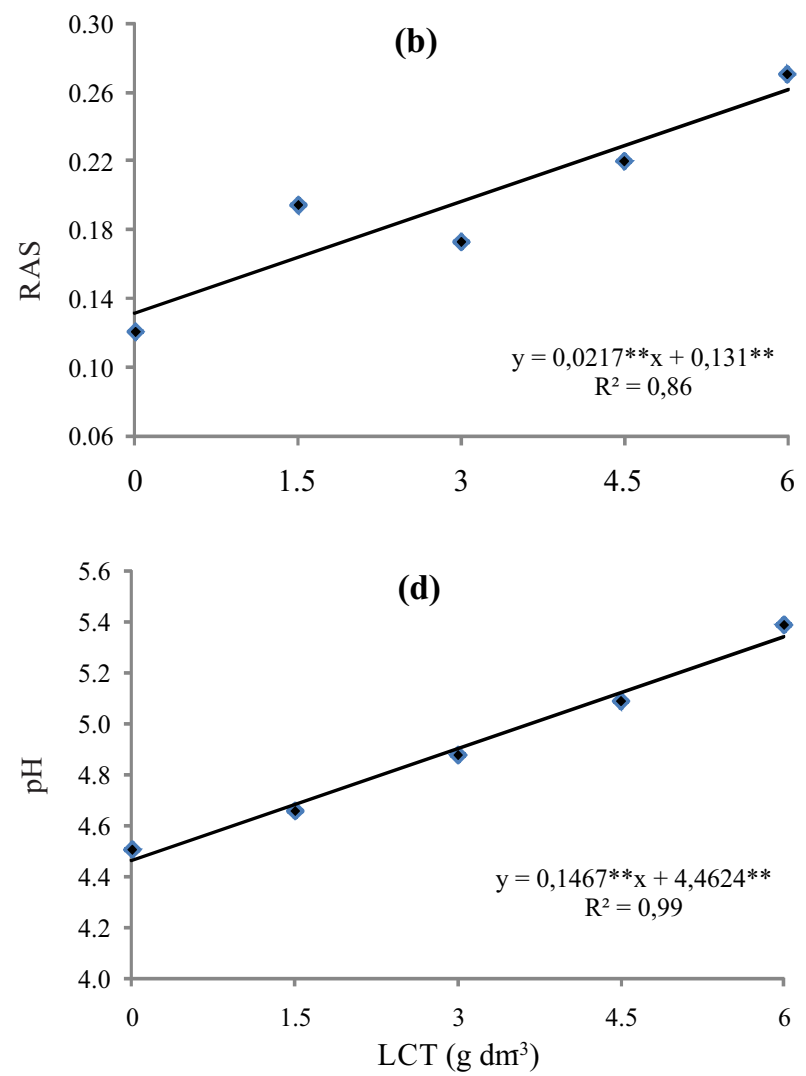

Figura 1 - Condutividade elétrica (a), relação de adsorção de sódio (b), porcentagem de sódio trocável (c) e pH do solo (d) após a adição do lodo de curtume e cultivo de Eucalyptus urophylla $(* * \mathrm{p}<0,01)$.

Figure 1 - Electrical conductivity (a), sodium adsorption ratio (b), exchangeable sodium percentage (c) and $p H(d)$ of the soil after the addition of tannery sludge and cultivation of Eucalyptus urophylla $(* * p<0.01)$.

Revista Árvore, Viçosa-MG, v.38, n.5, p.847-856, 2014 
O teor de cromo solúvel no solo, extraído com água, decresceu linearmente com o aumento das doses de LCT (Figura 2), correlacionando-se negativamente com o pH do solo $(-0,81 ; \mathrm{p}<0,01)$.

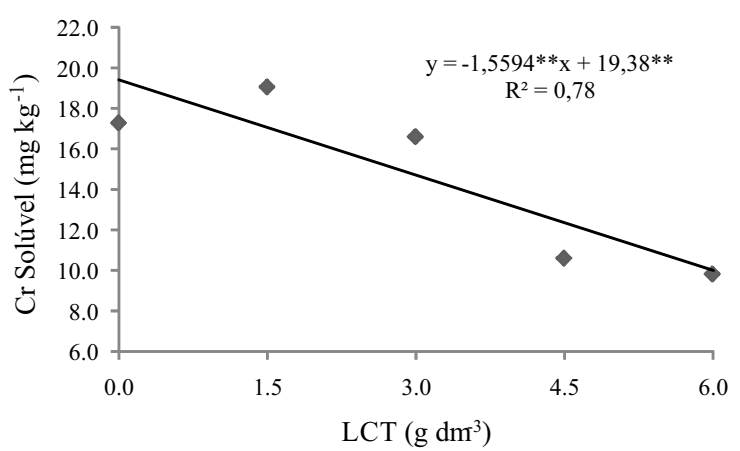

Figura 2 - Teor de cromo solúvel no solo incubado com lodo de curtume $(* * \mathrm{p}<0,01)$.

Figure 2 - Content of soluble chromium in soil incubated with tannery sludge (** $p<0.01)$.
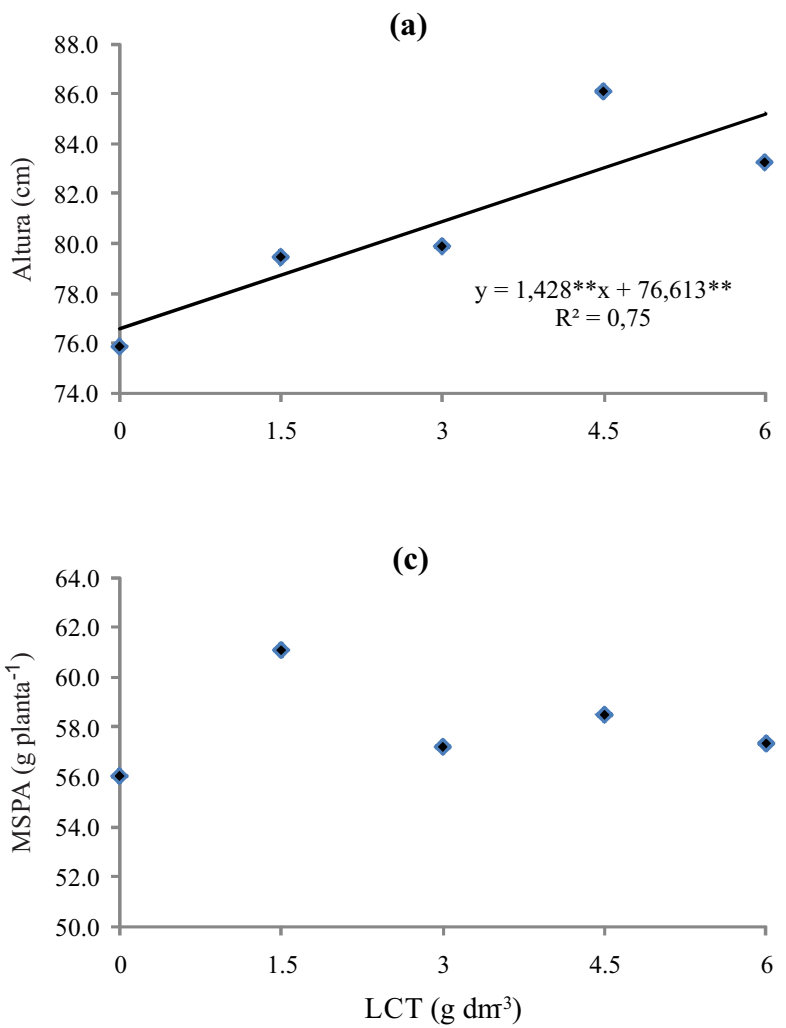

A adição do LCT proporcionou aumento linear em altura de até $11,5 \%$ em relação à testemunha, enquanto a produção de massa seca da raiz (MSR) decresceu, também linearmente, em média 28,3\% (Figura 3). Em todos os tratamentos, observou-se a presença de cromo nas raízes das plantas, aumentando o seu teor de forma linear com o incremento do LCT (Figura 4).

\section{DISCUSSÃO}

O aumento no $\mathrm{pH}$ do solo foi observado com o incremento das doses de LCT, o que pode ser atribuído à dissolução dos carbonatos e hidróxidos presentes no resíduo. Nessa reação, são liberados no solo a hidroxila e, também, cátions que promovem a troca com os íons $\mathrm{H}^{+}$e $\mathrm{Al}^{3+}$, resultando na diminuição das formas trocáveis desses e, assim, favorecendo a manutenção do pH mais elevado (SOUZA et al., 2007). Vários trabalhos têm salientado o aumento no $\mathrm{pH}$ proporcionado pela adição de lodo de curtume, associado ou não ao uso de calcário, o que depende da composição do lodo

(b)
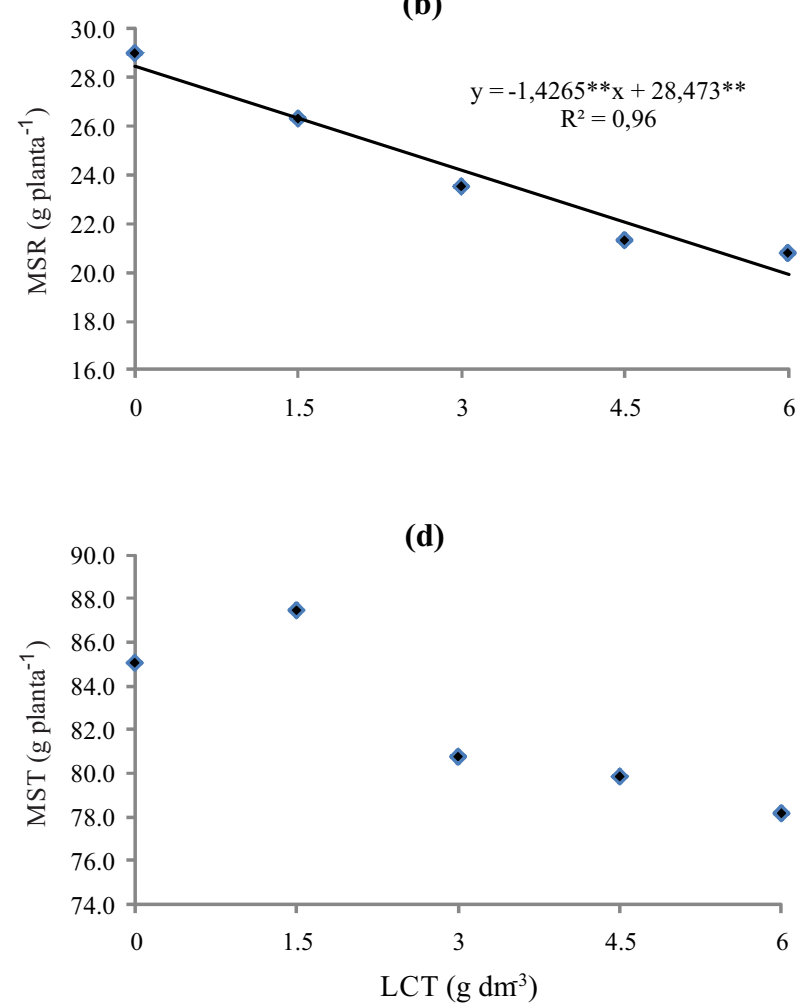

Figura 3 - Altura (a), massa das raízes secas (b), massa da parte aérea seca (c) e massa seca total (d) de mudas de Eucalyptus urophylla após 120 dias do transplantio $(* * \mathrm{p}<0,01)$.

Figure 3 - Height (a), root dry mass (b), shoot dry mass (c) and total dry mass (d) in Eucalyptus urophylla seedlings 120 days after transplanting $(* * p<0.01)$. 


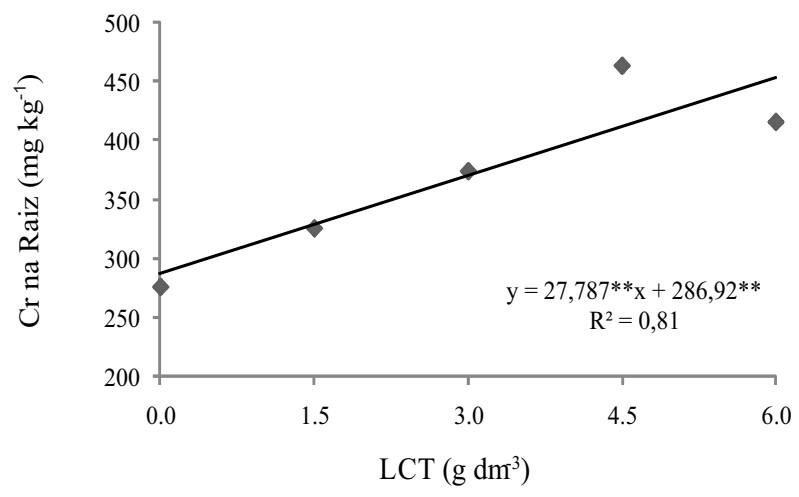

Figura 4 - Teor de cromo nas raízes de Eucalyptus urophylla, sob doses de LCT $(* * \mathrm{p}<0,01)$.

Figure 4-Content of chromium in the roots of Eucalyptus urophylla in doses of TS $\left({ }^{* *} p<0.01\right)$.

e da dose utilizada (COSTA et al., 2001; KONRAD; CASTILHOS, 2002; FERREIRA et al., 2003; TEIXEIRA et al., 2006).

O baixo pH no tratamento sem adição de lodo, mesmo com a aplicação de calcário, pode ser devido ao uso dos fertilizantes de reação ácida (SOUZA et al., 2007). Normalmente, o baixo pH não prejudica a produção de eucalipto, por ser uma espécie considerada tolerante à presença do alumínio nos solos ácidos (NEVES et al., 1982). Porém, o aumento do pH até os níveis obtidos neste trabalho certamente beneficiou o crescimento das plantas, seja pela maior disponibilidade de nutrientes, seja, ao mesmo tempo, pela redução na disponibilidade de metais, amenizando os efeitos tóxicos (RAIJ, 1991; VALERI et al., 1993; ROCHA et al., 2008), como verificado por Accioly et al. (2004), que, cultivando mudas de Eucalyptus camaldulensis em solos contaminados por Zn e Cd, observaram efeito atenuante na toxidez desses metais após a adição de calcário.

A CE correlaciona-se com os teores de sais dissolvidos em solução que são compostos, em grande parte, pelos cátions $\mathrm{Ca}^{2+}$, $\mathrm{Na}^{2+}$ e $\mathrm{Mg}^{2+}$ (MARSCHNER, 1995). Portanto, os mecanismos que proporcionem a retirada desses elementos da solução, como a absorção, adsorção e lixiviação, contribuem para a redução desse atributo. Dessa forma, os baixos valores da CE observados, apesar da aplicação de LCT, podem ser atribuídos, em parte, à alta (ALVAREZ V. et al., 1999) CTC do solo que, neste trabalho, foi de $12,2 \mathrm{cmol} \mathrm{dm}^{-3}$, em média. Abreu Junior et al. (2000), ao adicionarem composto de lixo em diferentes solos, perceberam que os menores aumentos na CE ocorreram quando a CTC inicial do solo era maior que $8 \mathrm{cmol}_{\mathrm{c}} \mathrm{dm}^{-3}$.

Quanto ao crescimento de plantas de eucalipto sob estresse salino, Mendonça et al. (2007) observaram diferença na tolerância quanto aos níveis de CE entre algumas espécies de eucalipto, sendo o crescimento das mudas de E. camaldulensis, E. pellita e E. robusta reduzido pelo aumento da salinidade, enquanto o de E. tereticornis não alterou em CE de até $8,3 \mathrm{dS} \mathrm{m}^{-1}$.

A RAS e a PST são importantes para verificar, respectivamente, a existência do predomínio dos teores de Na em relação aos de Ca e Mg e o nível de ocupação das cargas da CTC do solo por esse elemento, sendo diretamente associadas às propriedades físicas do solo, devido à tendência dispersiva dos coloides em presença do sódio (FREIRE; FREIRE, 2007). Dessa forma, a aplicação de calcário pode ter contribuído para os baixos valores observados de RAS e PST, pois a adição de Ca e Mg, por meio da calagem, possivelmente favoreceu a manutenção do equilíbrio dos íons no solo, evitando o predomínio de Na que está presente em elevado teor no LCT. Ressalta-se que os valores de pH, CE, RAS e PST observados foram menores que os limites estabelecidos na classificação do solo como salino e, ou, sódico (RICHARDS, 1954).

Segundo Kotas e Stasicka (2000), no intervalo de pH entre 4,0 e 5,5, o cromo é encontrado predominantemente como $\mathrm{Cr}(\mathrm{OH})^{2+}$, sendo facilmente adsorvido pelos coloides do solo. Afirmaram que, além de promover a precipitação dos metais, o incremento no pH também contribui para acréscimo das cargas negativas do solo, aumentando a adsorção do metal, o que evita a sua presença em solução. Gomes et al. (2001), estudando a adsorção de cromo e outros metais em sete tipos de solos do Brasil, verificaram que, frequentemente, o cromo foi o mais retido, e sua adsorção correlacionou positivamente com o pH e com a CTC do solo. Nesse sentido, o aumento do pH do solo devido à adição do lodo de curtume influenciou a disponibilidade do cromo, por meio da precipitação, reduzindo sua presença em solução.

Em trabalhos sobre o fracionamento do cromo em solos como os de Köleli (2004), Barra (2005), BarajasAceves et al. (2007) e Gupta e Sinha (2007), com e sem adição de resíduos contendo o metal, confirmaram que o teor solúvel ou disponível é pequeno em relação 
ao total de $\mathrm{Cr}$, devido à tendência do metal em formar precipitados e ser adsorvido covalentemente pelos coloides.

O cromo solúvel presente no solo sem adição de lodo (Figura 2) tem, provavelmente, origem nos minerais primários, os quais, por meio dos processos intempéricos, disponibilizam o metal no solo, que, em consequência do baixo valor de $\mathrm{pH}$ observado nesse tratamento, passou a ser encontrado na forma solúvel. No entanto, quando comparado ao teor de cromo total do Cambissolo utilizado (Tabela 1), a quantidade de cromo solúvel é pequena, o que deve ter relação com a predominância do metal como componente dos minerais do solo.

A tendência de redução do cromo solúvel, mesmo com o aumento da dose de LCT, pode estar associado à possível associação entre o metal e moléculas orgânicas de difícil degradação. Conforme relatado por Aquino Neto e Camargo (2000), o cromo presente no lodo encontra-se insolúvel ou complexado com as proteínas do tecido animal. Oliveira (2008) também constatou pequeno percentual $(<0,01 \%)$ de cromo no resíduo sólido da indústria de curtume solúvel em água e, segundo esse autor, a hidrofobicidade das longas cadeias orgânicas que compõem o lodo diminui a superfície de contato, tornando o metal pouco solúvel em água.

No solo, porém, com a ação decompositora dos microrganismos, algumas dessas cadeias orgânicas podem ser fragmentadas e mineralizadas, o que disponibilizaria o cromo para solução do solo. Dessa forma, o metal estaria sujeito a ser adsorvido ou precipitado, o que ocorre com maior intensidade em maiores valores de $\mathrm{pH}$, os quais foram obtidos com o aumento da dose de LCT, justificando a menor presença do cromo solúvel nos tratamentos com a adição do resíduo.

Os nutrientes adicionados pelo LCT podem ter aumentado a fertilidade do solo e influenciado na síntese de raiz das plantas que cresceram na presença do resíduo, o que justificaria o aumento na altura e na manutenção, em média, do diâmetro, da produção de massa seca da parte aérea (MSPA) e total (MST) entre os tratamentos, sendo esses iguais a 10,9 mm, 58,0 g planta $^{-1}$ e 82,2 g planta $^{-1}$, respectivamente (Figura 3). Ressalta-se que, durante o experimento, não foram observados sintomas visuais de deficiência nutricional ou de toxidez nas mudas de Eucalyptus urophylla.
Gonçalves (1995) verificou que as árvores de Eucalyptus grandis com maiores taxas de crescimento foram as de menor densidade de raízes finas, sendo esse comportamento atribuído à maior fertilidade do solo em que cresciam essas plantas. Conforme Marschner et al. (1996), em solos com baixa disponibilidade de nutrientes o crescimento radicular é favorecido, como forma de maximizar a absorção dos nutrientes limitantes.

A adição do resíduo certamente aumentou o teor de cromo no solo, que, mesmo não estando solúvel em água, pode ser encontrado em formas disponíveis às plantas, potencializada pela acidificação da rizosfera, resultado da extrusão de prótons $\left(\mathrm{H}^{+}\right)$pelas raízes, possivelmente aumentou a disponibilidade do metal e sua absorção pela planta (ZONTA et al., 2006).

A ausência do cromo (limite de detecção de 0,006 $\mathrm{mg} \mathrm{kg}^{-1}$ ) na parte aérea da planta possivelmente se deve ao fato de o teor do metal acumulado não ser suficiente para ultrapassar o potencial de acúmulo nas células das raízes. Conforme Adrian (apud BARTELLI, 2007), a elevação dos teores de cromo no solo pode afetar os mecanismos que regulam sua entrada na planta e, dessa forma, permitir sua translocação para as demais partes do vegetal. Gupta e Sinha (2006), cultivando gergelim (Sesamum indicum) em substrato contendo proporções de 0, 10, 25, 35, 50 e 100\% de lodo de curtume, observaram que houve incremento no teor do cromo nas raízes, no entanto somente a partir da dose de $35 \%$ o metal foi detectado na parte aérea.

As concentrações de cromo verificadas neste trabalho foram menores que as observadas por Santana (2007) em raiz de jenipapo cultivada em solução nutritiva, sendo iguais a 1.713 e $1.867 \mathrm{mg} \mathrm{kg}^{-1}$ quando se adicionaram $30 \mathrm{mg} \mathrm{L}^{-1} \mathrm{de} \mathrm{Cr}$ (III) e Cr(VI), respectivamente, o que possivelmente ocorreu devido à pronta disponibilidade do metal fornecido na solução. Nesse mesmo trabalho, o teor de cromo de aproximadamente $1.400 \mathrm{mg} \mathrm{kg}^{-1}$ na raiz de jenipapo crescendo em solução com concentração de $15 \mathrm{mg} \mathrm{L}^{-1}$ de Cr (III) não afetou o crescimento das plantas em relação à testemunha.

Apesar do relato do efeito prejudicial do cromo no crescimento de diferentes espécies vegetais neste trabalho, pelos motivos anteriormente discutidos, acredita-se que a presença do metal no eucalipto não tem relação com o comportamento no crescimento das plantas. É importante ressaltar que, quanto maior a produção de massa pelas raízes das plantas, menor

Revista Árvore, Viçosa-MG, v.38, n.5, p.847-856, 2014 
a concentração dos nutrientes, por isso podem ocorrer menores teores de nutrientes em raízes com maior massa seca, em comparação com aquelas de menor produção de massa (BARRETTI et al., 2008).

\section{CONCLUSÕES}

Nas condições em que foi realizado este trabalho, é possível concluir que:

O lodo de curtume tem potencial de uso em solos florestais, pois proporciona aumento no crescimento das plantas de eucalipto.

O cromo solúvel não reflete a biodisponibilidade do metal às plantas, visto que a diminuição da solubilidade não refletiu o aumento de sua absorção pela planta.

A absorção de cromo e seu acúmulo nas raízes de eucalipto não prejudicaram o crescimento das plantas.

A adição do lodo no solo acarreta aumento do $\mathrm{pH}$, da condutividade elétrica, da relação de adsorção de sódio e da porcentagem de sódio trocável do solo, sem provocar, no entanto, a salinidade.

\section{AGRADECIMENTOS}

À Coordenação de Aperfeiçoamento de Pessoal de Nível Superior (Capes), pelo apoio.

\section{REFERÊNCIAS}

ABREU JUNIOR, C. H. et al. Condutividade elétrica, reação do solo e acidez potencial em solos adubados com composto lixo. Revista Brasileira de Ciência do Solo, v.24, n.3, p.635-647, 2000.

ACCIOLY, A. M. A.; SIQUEIRA, J. O.; MOREIRA, F. M. S. Amenização do calcário na toxidez de zinco e cádmio para mudas de Eucalyptus camaldulensis cultivadas em solo contaminado. Revista Brasileira de Ciências do Solo, v.28, n.4, p.775-783, 2004.

ALLEONI, L. R. F.; BORBA, R. P.; CAMARGO, O. A. Metais pesados: da cosmogênese aos solos brasileiros. In: VITAL-TORRADO, P. et al. (Ed.). Tópicos em Ciência do Solo. Viçosa, MG: Sociedade Brasileira de Ciência do Solo, 2005. v.4. p.1-42.

Revista Árvore, Viçosa-MG, v.38, n.5, p.847-856, 2014
ALVAREZ V., V. H. et al. Interpretação dos resultados das análises de solos. In: RIBEIRO, A. C.; GUIMARÃES, P. T. G.; ALVAREZ V., V. H. (Ed.). Recomendações para o uso de corretivos e fertilizantes em Minas Gerais - $\mathbf{5}^{\mathrm{a}}$ aproximação. Viçosa, MG: Comissão de fertilidade do solo do Estado de Minas Gerais, 1999. p.25-32.

AQUINO NETO, V.; CAMARGO, O. A. Crescimento e acúmulo de crômio em alface cultivada em dois Latossolos tratados com $\mathrm{CrCl}_{3}$ e resíduo de curtume. Revista Brasileira de Ciências do Solo, v.24, n.1, p.225-235, 2000.

BARAJAS-ACEVES, M.; CORONA-HERNÁNDEZ, J.; RODRÍGUEZ-VEZQUEZ, R. Chromium fractionation in semi-arid soils amended with chromium and tannery sludge. Journal of Hazardous Materials, v.146, n.1, p.91-97, 2007.

BARRA, C. S. Extração sequencial de fósforo e metais pesados em Latossolo Vermelho Amarelo a partir da aplicação de lodo de esgoto. 2005. $190 f$. Dissertação (Mestrado em Agroquímica) Universidade Federal de Viçosa, Viçosa-MG, 2005.

BARRETTI, P. B. et al. Aumento da eficiência nutricional de tomateiros inoculados com bactérias endofíticas promotoras de crescimento. Revista Brasileira de Ciência do Solo, v.32, n.4, p.1541-1548, 2008,

BARTLETT, R. J. Chromium cycling in soils and water: links, gaps, and methods.

Environmental Health Perspectives, v.92, n.1, p.17-24, 1991.

BELLOTE, A. F. J. et al. Resíduos da indústria de celulose em plantios florestais. Boletim de Pesquisa Florestal, n.37, p.99-106, 1998.

BARTELLI, C. Efeitos da disposição de lodos de curtume no solo e na planta. 2007. 67f. Tese (Doutorado em Geociências e Meio Ambiente) - Universidade Estadual Paulista “Júlio de Mesquita Filho”, Rio Claro, 2007.

CAMARGO, O. A. et al. Métodos de análise química, mineralógica e física de solos. Campinas, Instituto Agronômico de Campinas, 1986. 94p. (Boletim Técnico, 106) 
COSTA, C. N.et al. Efeitos da adição de lodos de curtume sobre as alterações químicas do solo, rendimento de matéria seca e absorção de nutrientes em soja. Revista Brasileira de Agrociência, v.7, n.3, p.189-191, 2001.

\section{EMPRESA BRASILEIRA DE PESQUISA} AGROPECUÁRIA - EMBRAPA. Serviço nacional de levantamento e conservação de solos. Manual de métodos de análise de solo. Rio de Janeiro: 1997. 212p.

FERREIRA, D. F. SISVAR: um programa para análise e ensino de estatística. Revista Científica Symposium, v.6, n.2, p.36-41, 2008.

FERREIRA, A. S. et al. Alterações de atributos químicos e biológicos de solo e rendimento de milho e soja pela utilização de resíduos de curtume e carbonífero. Revista Brasileira de Ciência do Solo, v.27, n.4, p.755-763, 2003.

FREIRE, M. B. G. S.; FREIRE, F. J. Fertilidade do solo e seu manejo em solos afetados por sais. In: NOVAIS, R. F., et al. (Ed.). Fertilidade do solo. Viçosa, MG: Sociedade Brasileira de Ciência do Solo, 2007. p.929-954.

GOMES, P. C. et al. Sequence and competitive adsorption of heavy metals by Brazilian soils. Soil Science Society of America Journal, v.65, p.1115-1121, 2001.

GONÇALVES, J. L. M. Sistema radicular de adsorção de Eucalyptus grandis sob diferentes condições edáficas. Silvicultura, v.17, n.61, p.8-10, 1995.

GUPTA, A. K.; SINHA, S. Chemical fractionation and heavy metal accumulation in the plant of Sesamum indicum (L.) var. T55 grown on soil amended with tannery sludge: Selection of single extractants. Chemosphere, v.64, n.1, p.161-173, 2006.

GUPTA, A. K.; SINHA, S. Phytoextraction capacity of the plants growing on tannery sludge dumping sites. Bioresource Technology, v.98, n.9 p.1788-1794, 2007.

IRVINE, S. A.; REID, D. J. Field prediction of sodicity in dryland agriculture in Central Queensland, Australia. Australian Journal of Soil Research, v.39, n.6, p.1349-1357, 2001.
KÖLELI, N. Speciation of chromium in 12 agricultural soils from Turkey. Chemosphere, v.57, n. 10, p.1473-1478, 2004.

KONRAD, E. E.; CASTILHOS, D. D. Alterações químicas do solo e crescimento do milho decorrentes da adição de lodos de curtume. Revista Brasileira de Ciência do Solo, v.26, n.1, p.257-265, 2002.

KOTAS, J.; STASICKA, Z. Chromium occurrence in the environment and methods of its speciation. Environmental Pollution, v.107, n.3, p.263283, 2000.

MARSCHNER, H. Mineral nutrition of higher plants. 2.ed. London: Academic Press, 1995. 889p.

MARSCHNER, H.; KIRKBY, E. A.; CAKMAK, I. Effect of mineral nutritional status on shoot-root partioniting of photoassimilates and cycling of mineral nutrients. Journal of Experimental Botany, v.47, p.1255-1263, 1996. Special Issue.

MENDONÇA, A. V. R. et al. Características biométricas de mudas de Eucalyptus sp sob estresse salino. Revista Árvore, v.31, n.3, p.365-372, 2007.

MINITAB, Inc. Minitab statistical software $^{\mathrm{TM}}$, Release 14.13. Copyright $@ 1972$ - 2004.

NEVES, J. C. L.; NOVAIS, R. F.; BARROS, N. F. Efeito do alumínio em solução nutritiva no crescimento e absorção de nutrientes por Eucalyptus spp. Revista Árvore, v.6, n.1, p.116, 1982.

NOVAIS, R. F.; NEVES, J. C. L. \& BARROS, N. F. Ensaio em ambiente controlado. In: OLIVEIRA, A. J. et al. Métodos de pesquisa em fertilidade do solo. Brasília: Embrapa/SEA, 1991. p.189-254.

OLIVEIRA, R. C. Contaminação do solo por alguns resíduos de curtume. 2008. $137 \mathrm{f}$. Tese (Doutorado em Solos e Nutrição de Plantas) Universidade Federal de Viçosa, Viçosa, MG, 2008.

RAIJ, B. van. Avaliação da fertilidade do solo. Piracicaba: Associação Brasileira para Pesquisa da Potassa e do Fosfato, 1981. 142p.

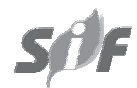

Revista Árvore, Viçosa-MG, v.38, n.5, p.847-856, 2014 
RAIJ, B. van. Fertilidade do solo e adubação. Piracicaba: Ceres, 1991. 343p.

RICHARDS, L. A. (Ed.) Diagnosis and improvement of saline and alkali soils. Agriculture Handbook, v.60, p.160, 1954.

ROCHA J. B. O. et al. Efeito da calagem na nutrição mineral e no crescimento inicial do eucalipto a campo em Latossolo Húmico da Zona da Mata (MG).

Scientia Forestalis, v.36, n.80, p.255-263, 2008.

\section{SANTANA, K. B. Respostas}

morfofisiológicas de Genipa americana $L$. ao cromo tri e hexavalente: avaliação de seu potencial fitorremediador. 2007. 48f.

Dissertação (Mestrado em Desenvolvimento Regional e Meio Ambiente) - Universidade Estadual de Santa Cruz, Ilhéus, 2007.

SILVA, C.A.; RANGEL, O. J. P.; BELIZÁRIO, M. H. Interação calagem-adubação fosfatada e sua influência nos níveis críticos de $\mathrm{P}$ e crescimento do eucalipto. Scientia Forestalis, v.73, n.1, p.63-72, 2007.

SILVA, F. C. (Org.) Manual de análises químicas de solos, plantas e fertilizantes. Brasília: Embrapa Solos/Embrapa Informática Agropecuária/Embrapa Comunicação para Transferência de Tecnologia, 1999. 370 p.
SOUZA, D. M. G.; MIRANDA, L. N.; OLIVEIRA, S. A. Acidez do solo e sua correção. In: NOVAIS, R. F. et al. (Ed.) Fertilidade do solo. Viçosa, MG: Sociedade Brasileira de Ciência do Solo, 2007. p.205-274.

TEDESCO, M. J. et al. Análises de solo, plantas e outros materiais. 2.ed. Porto Alegre: Universidade Federal do Rio Grande do Sul, 1995. 215p.

TEIXEIRA, K. R. G. et al. Efeito da adição de lodo de curtume na fertilidade do solo, nodulação e rendimento de matéria seca do caupi. Revista Ciência Agrotécnica, v.30, n.6, p.1071-1076, 2006.

VALERI, S. V.; AGUIAR, I. B.; CORRADINI, L. Composição química foliar e crescimento volumétrico de Eucalyptus grandis Hill ex Maiden cultivado em areia quartzosa, em resposta à aplicação de fósforo e calcário dolomítico. IPEF, n.46, p.63-75, 1993.

ZONTA, E. et al.. O sistema radicular e suas interações com o ambiente edáfico. In: FERNANDES, M. S. (Ed.) Nutrição mineral de plantas. Viçosa, MG: Sociedade Brasileira de Ciência do Solo, 2006. p. 355-374. 